\title{
Cardiovascular Effects of Androgens
}

\author{
Carlos Wilson, Rodrigo Maass and Manuel Estrada \\ Universidad de Chile, Facultad de Medicina, Instituto de Ciencias Biomédicas \\ Chile
}

\section{Introduction}

Androgens are the male sex hormones responsible for development of the male reproductive system. Testosterone is the main androgen, however, other circulating androgens also exist; these are dehydroepiandrosterone, androstenedione and androstenediol. In some tissues, testosterone can be converted to dihydrotestosterone by action of 5a-reductase. Testosterone is also found in females, but at much lower levels than males; it can be converted into estradiol by the enzyme aromatase. Testosterone has 19 carbon atoms, and is produced from cholesterol, mainly by Leydig cells in the testes. Androgens are responsible for primary and secondary sexual characters in men, and also for the development of skeletal muscle mass and strength, erythropoiesis and bone density, amongst other functions.

The divergent effects that androgens have between sexes can be explained by differences in concentration, metabolism and receptor expressions. Male sex hormones are also known to fluctuate along the day and throughout life. Prior to puberty, testosterone level is usually low in males. However, after puberty, testosterone level increases and reaches its peak around the age of 20-25 in men. As aging occurs, testosterone levels decline.

Testosterone and its derivatives are well known for their androgenic properties and anabolic effects. These hormones direct the differentiation of organs and tissues towards the adoption of male phenotypes. Thus far, the effects of androgens on the cardiovascular system remain incompletely understood. Some studies point to increased cardiovascular risk associated with a high circulating androgen level, related to responses that lead to changes in blood pressure, ion channel activity and cardiomyocyte hypertrophy. However, other studies support a long-term cardio-protective role for these steroid hormones. Despite these differences, increasing clinical evidence supports consideration for transient use of testosterone derivatives to improve cardiovascular function.

\section{Mechanism of androgen action}

Androgens exert most their effects through the direct binding to specific intracellular receptors acting as transcriptional activators (Beato, 1989). Intracellular androgen receptors have been described in neonatal and adult cardiomyocytes (Hickson et al., 1984; Marsh et al., 1998). Genomic responses to testosterone are mediated through the intracellular androgen receptor, which is a 110-kDa protein with domains for androgen binding, nuclear localization, DNA binding, and transactivation (TD). The conserved domain structure has three major functional regions: an NH-terminal transactivation domain, a centrally located 
DNA binding domain (DBD), and a $\mathrm{COOH}$-terminal hormone-binding domain (HBD) (Figure 1). The $\mathrm{COOH}$-terminus contains an additional activation domain and a hinge region connecting the $\mathrm{HBD}$ and the DBD. Upon ligand binding, the nuclear receptors translocate to the nucleus where they dimerize and bind to regulatory DNA sequences on target genes and activate transcription (Simental et al., 1992). Several co-regulatory proteins that bind and regulate the activity of receptors have been identified. These include both coactivators that positively regulate transcriptional effects of intracellular receptors after ligand binding and co-repressors that negatively regulate receptor activity. These effects are slow, with a latency period before onset, but they are also long lasting, remaining active for hours after hormone stimulation.

In addition to this transcriptional or genomic mode of action, increasing evidence suggests that androgens can exert rapid, non-genomic effects. The time course of these responses is not compatible with the classic genomic mechanism for the action of steroids, since they have a rapid onset without an apparent latency period. Common to these early effects is a fast increase in intracellular $\mathrm{Ca}^{2+}$ and activation of $\mathrm{Ca}^{2+}$-dependent pathways and second messenger cascades (Estrada et al., 2000, 2003). Second messenger induction by nongenomic steroid action is insensitive to inhibitors of either transcription or translation. Little is known about these non-genomic effects in cardiac cells. However, these responses involve the generation of different patterns of $\mathrm{Ca}^{2+}$ signals and also in the activation of complementary $\mathrm{Ca}^{2+}$-dependent pathways. Thus, in addition to the classical mechanism of steroid action in cardiac cells, androgens activate additional specific signal transduction pathways (Altamirano et al., 2009; Vicencio et al., 2006). An interesting hypothesis is that these second messenger cascades may ultimately serve to modulate the transcriptional activity of the intracellular androgen receptor and its associated global response. This idea of an integrated mechanism for androgen action will be discussed.

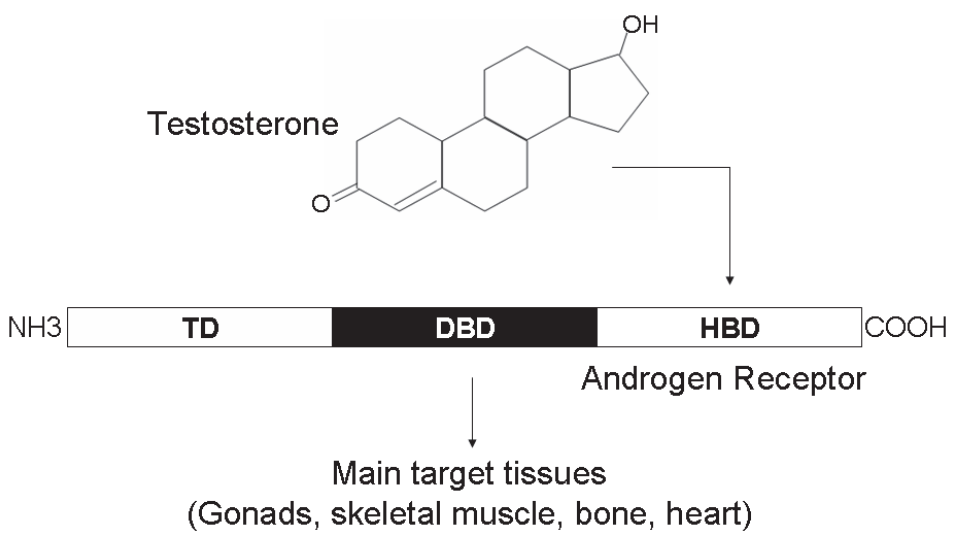

Fig. 1. Schematic representation of testosterone and the main domains of intracellular androgen receptor.

\section{Cardiovascular effects of androgens}

Androgens influence cardiac function by acting directly on the heart or by affecting the vascular system (English et al., 2001; Hayward et al., 2001; Jones et al., 2003; Kienitz \& 
Quinkler, 2008). In humans and experimental animals, anabolic steroids have been associated with an increased risk of coronary artery disease by adversely affecting the plasma lipid and lipoprotein profile, producing thrombosis and cardiac hypertrophy (Liu et al., 2003; Sullivan et al., 1998). In particular, use of elevated doses of testosterone or its synthetic cognates has been related to cardiac hypertrophy, ventricular remodelling, cardiomyopathy, myocardial infarction, and sudden cardiac death. On the other hand, with a normal steroid level, androgen actions are necessary for a range of developmental and biological processes, including maintaining the health of cardiomyocytes. Androgens might also produce additional hemodynamic effects by relaxing vascular bed, reducing after-load and rapidly increasing cardiac contractility, resulting in increased cardiac output (Liu et al., 2003). This dual androgen effect is not clear yet. Research in the field of androgens and androgen receptors signaling pathways will provide considerable understanding of the physiological and pathological roles of these hormones. These effects could be related to different concentrations of these hormones as well as to differential activation of signal transduction pathways.

Both beneficial and pathological effects of androgens are observed clinically. Patients with chronic heart failure suffer considerable morbidity as well as early mortality. They exhibit altered structure and function of cardiac and skeletal muscle and excessive activation of catabolic hormones and inflammatory cytokines (Malkin et al., 2004). Men with chronic heart failure have relatively low androgen levels, which may contribute to the pathophysiological process.

\subsection{Role of androgens in hypertension}

Hypertension is a major risk factor for developing cardiovascular disease, atherosclerosis and sudden cardiac death. Hypertension is more prevalent and occurs earlier in men than in women. Blood pressure is elevated from the onset of puberty in males, when they manifest the effects and differences of sex steroids. These differences in blood pressure between men and women are maintained until 60 years of age. Epidemiological data indicate that systolic blood pressure in men under the age of 60 years is 6-7 mm Hg higher than in women, and diastolic pressure is higher by 3-5 mm Hg (Stamler et al., 1976). In women over the age of 60 , show gradual increases of blood pressure over a period of 5 to 20 years, until hypertension is highly prevalent in women as in men. Estrogen reduction after menopause is partially responsible for this effect and experimental data indicate that the change in the estrogen/androgen ratio seems to be the cause (Akkad et al., 1997; Pripp et al., 1999).

Epidemiological studies show that androgens are important determinants of sex differences in blood pressure. An elevated level of anabolic steroids, found in anabolic abuse by high performance athletes has been associated with hypertension, cardiac remodelling and myocardial ischemia (Kienitz \& Quinkler, 2008). This suggests a direct role in the development of hypertension. However, clinical evidence shows beneficial effects of testosterone on hypertension. Observational studies in humans indicate that there is an inverse relationship between systolic pressure and the plasma level of testosterone in men. There is also higher incidence of hypertension in individuals with reduced free circulating androgen (Fogari et al., 2005). The beneficial effect of testosterone replacement has also been well documented. Accordingly, in randomized, double-blind, case-control clinical studies hormone administration was related to the reduction of vascular tone (Malkin et al., 2006). In other study, administration of testosterone significantly reduced ST segment depression 
in patients with stable angina and improved post-exercise myocardial perfusion in patients with occlusive coronary artery disease (Jaffe, 1977).

Furthermore, experimental evidences provide controversial information. In some animal models potential role for androgens in the pathogenesis of hypertension have been observed. Mice hypertension models show that castration and subsequent testosterone supplementation at high doses produce the onset of hypertension (Dubey et al., 2002). This effect is mediated by androgen receptors, as shown by the inhibitory effect of flutamide, an antagonist of the intracellular androgen receptor. However, others in vitro studies indicate a direct vasodilator effect of androgens by the activation of the nitric oxide (NO) pathway mediated by the endothelium, activation of voltage-dependent potassium channels and blockage of voltage and receptor-operated calcium channels (Jones et al., 2003, 2004).

Thus, androgens appear to be involved in the regulation of vascular tone. Aging induces a progressive reduction in the plasma testosterone levels along the years, which begins to be deleterious as aging occurs; while physiological stress produces acute diminution of androgen levels. These conditions are determinants for clinical manifestation of hypertension. Therefore, testosterone supplementation in men with low levels of androgens could be beneficial to restore altered blood pressure (Handelsman \& Liu, 2005).

\subsection{Androgens in endothelial function, atherosclerosis and heart perfusion}

Numerous clinical studies show that men exhibit higher susceptibility to atherosclerosis than pre-menopausal women. The available information indicate that the evolution of atherosclerosis is faster in males - independent of dyslipidemia or evidence of endothelial damage - than females (Kaushik et al, 2010.). However, a negative correlation between testosterone plasma level and cardiovascular disease in men has been observed (Iliescu \& Reckelhoff, 2006; Thijs et al., 2003). Testosterone deficiency affects approximately $30 \%$ of men under 30 years and as aging occurs, testosterone level decline even more, a male condition known as andropause (Handelsman \& Liu, 2005). Low androgen concentrations are strongly associated with increase in cardiovascular risks including atherogenic lipid profile, insulin resistance, obesity and prothrombotic profile (Jones et al., 2005; Kapoor et al., 2007). However, other studies indicate that testosterone increases cholesterol uptake by macrophages promoting its transformation into foam cells, which are involved in the formation of atheroma lesions (McCrohon et al., 2000). Testosterone also induces apoptosis of endothelial cells in vitro and promotes proliferation and migration of vascular smooth muscle cells, which are involved in the development of atherosclerotic lesions (Kaushik et al., 2010).

This appears to explain the faster progression of atherosclerosis occurring in men than women. However, the amount of clinical evidence suggests protective effects of androgens during atherosclerosis. For example, high to normal range of testosterone concentrations exhibit preventive role in coronary artery disease. In fact, patients with coronary artery disease show significantly lower testosterone level than patients without coronary artery disease (English et al., 2000). Animal models show similar results (Alexandersen et al., 1999). At cellular level, the mechanism for these testosterone effects involve inhibition of macrophage migration, which decrease the expression of adhesion molecules and proinflammatory cytokines such as TNFa (Malkin et al., 2004).

In addition, androgens produce direct and rapid vasodilatory effects in human coronary disease and stable angina, increasing the coronary flow between 12 and 17\% (Webb et al., 1999). This has not been free of controversy, because in isolated vessels the chronic 
treatment with testosterone produce increase in the vasoconstrictor responses to adrenergic agonists, while reduce the response to nitric oxide (Iliescu \& Reckelhoff, 2006; Malkin et al., 2006). In animal models, testosterone produces a similar effect, independent of androgen receptor. Vasodilatation occurs by inhibition of plasma membrane calcium channels and activation of potassium channel (Ding \& Stallone, 2001). However, this effect is acute and only produced in response to high doses of testosterone, so this does not appear to be an appropriate strategy for anti-ischemic treatment. But this could explain the positive effects on peripheral vascular resistance in response to acute administration of testosterone in men with heart failure, stable angina or in arteries isolated from healthy men with heart failure.

Thus, current data indicate that androgens, particularly testosterone, do not have a permissive role in the evolution of atherosclerotic lesions at the cellular level. However, testosterone diminution as in aging is associated with accelerated atherosclerosis. This occurs by increase in the expression of adhesion molecules and pro-inflammatory cytokines. Moreover, this also could be stimulated by high exogenous androgen supplementation.

\subsection{Effects of testosterone on cardiac excitability}

Gender differences are well-established in the generation of ventricular arrhythmias associated with a prolonged QT interval. This interval is used to estimate the electrocardiographic duration of ventricular action potential. Thus, women exhibit greatest risk of ventricular arrhythmias such as "torsade de pointes", a type of highly fatal polymorphic ventricular tachycardia. This clinical condition is worse in women compared with men, particularly in response to drugs that prolong the QT interval (Rautaharju et al., 2006). This has been associated with sex differences in the rate of ventricular repolarization being slower in adult women. These differences are manifested from puberty, becoming the QT interval increasingly longer until women reach adulthood. In men, once they start to drop in plasma testosterone levels gradually prolong the QT interval similar to women older than 60 (Zhou et al., 1992). Studies in experimental animals have established that testosterone levels are negatively correlated with the duration of the action potential (Pham et al., 2001) and other researchers reported that dihydrotestosterone administration in castrated male rabbits shortened QT interval (Liu et al., 2003).

This information indicates that testosterone is a regulator of sex differences in the action potential duration, ventricular repolarization and propensity to ventricular arrhythmias. In isolated cardiomyocytes has been established that testosterone increases the expression of $\beta$ adrenergic receptors, L-type calcium channel and sodium-calcium exchanger (Golden et al., 2004). Moreover, testosterone increases by 30\% the density of repolarizing potassium currents, which is due to changes in both gating kinetics of the delayed rectifier potassium currents (Ikr) and shortening the duration of the QT interval (Liu et al., 2003)

Testosterone has been shown to interact directly with the NO system. Activation of this pathway induces shortening in the duration of the action potential by activating the slow component of delayed rectifier potassium current (Iks) and inhibiting L-type calcium currents (Ica,L) (Bai et al., 2004, 2005).

\section{Androgen-mediated cardiac hypertrophy}

The most striking evidence of cardiac effect of androgens is the case of highly conditioned athletes, which have died by sudden cardiac death. Post mortem examinations indicated anatomical abnormalities in the heart, known as hypertrophic cardiomyopathy (Maron et 
al., 1978, 1980). Thus, it was assumed that elevated testosterone administration induces cardiac hypertrophy.

Cardiac hypertrophy is an adaptive mechanism to enhance cardiac output in response to cardiovascular challenges. Cardiac hypertrophy is produced in response to several pathophysiological conditions, such as mechanical stretching or neuro-hormoral deregulation. This process is characterized by increases in cardiomyocyte size and protein synthesis, as well as by the re-expression of various fetal genes (Frey \& Olson, 2003; Izumo et al., 1987). At the cellular level, cardiomyocytes depend of the activation of several signalling pathways related to cell growth, which are crucial for the development of cardiac hypertrophy. These pathways involve both androgen receptors as well as intracellular signalling pathways.

\subsection{Androgen receptor in hypertrophy}

Cellular effects of testosterone depend on activation of androgen receptor, which is localized in cytoplasm and acts as a transcriptional factor when it binds testosterone. Marsh et al. have shown that androgens produce cardiac hypertrophy by a direct, receptor-specific mechanism (Marsh et al., 1998). They have also revealed that androgens regulate functional expression of an L-type calcium channel in isolated rat ventricular cardiomyocytes, leading to a modulation of cardiac performance in males. Li et al. reported that either castration or administration of flutamide, an androgen receptor antagonist, markedly attenuated cardiac hypertrophy and fibrosis in guanylyl cyclase-A knock-out male mice (Li et al., 2004). In baroreceptor-denervated rats, left ventricular hypertrophy is gender-dependent and elevated testosterone stimulates cardiac hypertrophy (Cabral et al., 1988a, 1988b). Moreover, in vitro studies provide evidence that androgens induce hypertrophic growth in cultured cardiomyocytes, suggesting that the growth promoting effect is direct (Marsh et al., 1998). The hypertrophic effects of testosterone are associated with increased protein synthesis mediated by the androgen receptor and specific nuclear coactivators related to cell growth (Hickson et al., 1984).

\subsection{Intracellular signaling pathways}

Pro-hypertrophy stimuli activate diverse intracellular signaling pathways. Activation of these pathways by androgens could lead to long-term cellular effects by activation of cotranscriptional modulators. Induction of multiple signaling pathways in cardiac hypertrophy has been described as follows:

\section{$\mathrm{Ca}^{+2} /$ Calcineurin/NFAT pathway}

Calcium ion $\left(\mathrm{Ca}^{+2}\right)$ is one of the most diverse and important intracellular second messenger as well as a key element in the excitation-contraction coupling of cardiac muscle. $\mathrm{Ca}^{+2}$ has been related to cardiac hypertrophy, because of its ability to promote the activation of the protein phosphatase calcineurin through establishment of $\mathrm{Ca}^{+2} /$ calmodulin complex (Heineke \& Molkentin, 2006). Calcineurin promotes the translocation of the nuclear factor of activated T cells (NFAT) from cytoplasm to nucleus. NFAT family proteins are responsible for the expression of c-fos, c-jun and c-myc, early fetal genes; which are expressed during fetal development. These are silenced in adult stages and then re-expressed during cardiac hypertrophy, reason why they are considered as hypertrophic markers (Frey \& Olson, 2002, 2003; Heineke \& Molkentin, 2006).

\section{PI3K/Akt/GSK3- $\beta$ pathway}

Another cellular pathway involved in cardiac hypertrophy is PI3-K (Phosphoinositide 3kinase)/Akt proteins. This signalling pathway has been related to cell survival and 
proliferation in almost all cell types. However, the up-regulation of the pathway by several stimuli induces cardiac hypertrophy. One of the most common downstream targets of Akt is the protein kinase GSK3- $\beta$ (Glycogen Synthase Kinase 3- $\beta$ ) (Antos et al., 2002). Activated GSK3- $\beta$ phosphorylates several members of NFAT family, which promotes their translocation from nucleus to cytoplasm. Akt phosphorylates and inhibits GSK3- $\beta$, which increases the residence of NFAT in the nucleus. Also, Akt has the ability to phosphorylate the protein mTOR (mammalian target of rapamycin), another downstream target of PI3K/Akt pathway. In cardiac cells, protein synthesis is highly regulated by mTOR, which stimulates protein translation and ribosome biosynthesis (Proud, 2004). mTOR lies upstream of critical translation regulators such as the 40S ribosomal protein S6 kinase 1 (S6K1) and the eukaryotic initiation factor 4E-binding protein 1 (4E-BP1). Activation of the mTOR pathway is a critical step to induce cardiac hypertrophy in vitro (Altamirano et al., 2009; Takano et al., 1996) and in vivo (Shioi et al., 2003).

\section{G-protein-coupled receptors pathway}

Plasma membrane G-protein G-protein-coupled receptors (GPCR) are crucial for cardiac function and hypertrophic growth. Both Gas and Gaq are sufficient to produce cardiac hypertrophy. Gas induces the synthesis of cAMP and PKA activation, which could induce hypertrophy. Gaq promotes the activation of the protein phopholipase $\mathrm{C}(\mathrm{PLC})$ and $\mathrm{IP}_{3}$ production, which induces intracellular $\mathrm{Ca}^{+2}$ oscillations and hence, the activation of different proteins responsible of cardiac hypertrophy, such as calcineurin (Heineke \& Molkentin, 2006).

These signalling pathways are related to the hypertrophic growth of cardiomyocytes. It has been described that testosterone induces intracellular $\mathrm{Ca}^{2+}$ increase through a nongenomic action mechanism, as we discussed earlier in this chapter. Studies in cultured cardiomyocytes show that through a nongenomic mechanism, testosterone is implicated in the activation of a membrane receptor coupled to a Gaq protein, thus resulting in the production of $\mathrm{IP}_{3}$ and $\mathrm{Ca}^{+2}$ release from endoplasmic reticulum (Vicencio et al., 2006). Then, calcium oscillations induce the activation of the mitogen-activated protein kinase ERK 1/2, which in turns phosphorylates mTOR, promoting hypertrophic cardiac growth (Altamirano et al., 2009).

Aside from classical action mechanism for testosterone, non-classical effects also are implicated in cardiac hypertrophy development has been described. The establishment of testosterone-androgen receptor complex acts as a transcriptional factor for the expression of different genes and proteins necessary for protein synthesis, energy production and cell growth, which are crucial for hypertrophic growth.

\subsection{Cardiac remodelling}

Cardiac remodelling involves changes in the structure, mass and function of the heart, mainly due to increase in the number of myofibrils or cardiomyocyte hypertrophy. Proliferation of cardiac fibroblasts and consequent increase in the extracellular matrix is called cardiac fibrosis. The balance between synthesis and degradation of different collagen types determine the content of extracellular matrix proteins. Cardiac fibrosis increases the stiffness of the heart chambers, which produce high end diastolic pressure. If this event is persistent, leads to progressive and irreversible cardiac damage and heart failure. Controversial information exists about the role of sex hormones on cardiac remodelling during cardiac hypertrophy, including fibrosis. However, these differences are manifested 
as gender differences in cardiac remodelling. Heart size of men is bigger than women, even when is corrected for body weight. Men also have higher incidence of fibrosis; however direct effects of androgens are not clear. The increase in cardiac mass is higher in men from puberty and has been shown that estrogens have preventive effects on cardiac hypertrophy (Weinberg et al., 1999). In castrated mice, administration of androgen receptor antagonists does not abolish the sex differences in heart size or cardiac fibrosis ( $\mathrm{Li}$ et al, 2004), suggesting that androgens are not the only determinants for these differences. Negative consequences of fibrosis are mediated mainly by local effect of the renin-angiotensin system. Angiotensin II regulates differentiation and proliferation of ventricular fibroblasts and synthesis of extracellular matrix, which consist mainly of collagen type I and III (Krenning et al., 2010). The synthesis of collagen type I and III by fibroblasts is stimulated by TGF- $\beta 1$ and inhibited by androgens (Ikeda et al., 2005). Cardiac fibroblasts express androgen receptor, which suggest a role for androgens during cardiac remodelling. Experimental evidence in androgen receptor knockout (ARKO) mice show reduced ventricular volume and wall thickness, but no differences in blood pressure or heart rate as compared with normal animals (Ikeda et al., 2005). It has also been demonstrated that dihydrotestosterone increase atrial natriuretic peptide (ANP) secretion from neonatal rat cardiomyocytes (Marsh et al., 1998). Furthermore, ARKO mice show a significant reduction in ANP gene transcription, resulting in increased cardiac fibrosis. On the other hand, testosterone has been shown to increase the amount of collagen measured around coronary blood vessels contributing to fibrosis in male hypertensive rats independent of the reninangiotensin system. Cavasin et al. (2006) have determined that high testosterone levels enhance acute myocardial inflammation, adversely affecting myocardial healing and early remodelling (Cavasin et al., 2006). Even when the evidence is still controversial, androgens show a protective role on cardiac remodelling and protect the heart from maladaptive fibrosis, preventing the deleterious effects of increased pre- and after-load induced by angiotensin II.

\section{Cardiac metabolism}

Normal heart requires a continuous supply of energy to maintain muscle contraction as well as hemodynamic adaptation, survival, growth and metabolism. Neuro-hormonal activation is an important input for cardiovascular response to metabolic demands. Although initially adaptive, neuro-hormonal activation together with metabolic alterations has deleterious effects on cardiovascular system.

In the heart muscle, ATP production is crucial for all cellular and contractile process. In the adult heart, ATP comes mainly from the $\beta$-oxidation of fatty acids, an oxygen dependent process. The $10-40 \%$ remaining come from glucose degradation through glycolysis, an oxygen independent process (Neglia et al., 2007; Stanley et al., 2005).

$\beta$-oxidation depends upon fatty acids uptake, which occurs through different fatty acid translocases located in the plasma membrane, like CD36 protein. Fatty acids must be transported to the mitochondria for $\beta$-oxidation, which occurs through the enzyme carinitine palmitoyl transferase-1 (CPT-1). Once inside mitochondria, fatty acids are oxidized to produce acetil-CoA, which will be incorporated into Krebs cycle for NADH, $\mathrm{FADH}_{2}$ and $\mathrm{CO}_{2}$ production. These intermediates provide oxidative power during the oxidative phosphorylation in mitochondria, where ATP is finally produced by ATP synthase complex V. 
On the other hand, glycolysis requires glucose uptake, which occurs through the glucose transporters 1 and 4 (GLUT1 and GLUT4), the main glucose transporters in cardiac cells. Once inside the cell, the enzymes hexokinase and phosphofructokinase, the glycolysis pacemaker enzyme, lead the conversion of glucose to pyruvate. Through this process 2 ATP molecules are generated from each glucose molecule incorporated.

However, the heart muscle is able to modify the ratio between $\beta$-oxidation and glycolysis in response to pro-hypertrophic agents (Stanley et al., 2005). For example, cardiac hypertrophy due to pressure overload is accompanied of a reduction in $\beta$-oxidation and an increase in the glycolytic rate as a compensatory mechanism that improves ATP production in the heart muscle (van der Vusse et al., 2000, 2002). In contrast, individuals with uncompensated diabetes usually develop a different cardiac hypertrophy, known as diabetic cardiomyopathy. Since diabetic patients are not able to metabolize glucose, diabetic cardiomyopathy is characterized by an increase in the fatty acids assimilation by cardiac cells, which carry cardiac lipotoxicity (van der Vusse et al., 2000).

During heart failure, cardiac muscle is not able to produce enough ATP for cardiac contraction, resulting in poor contractile performance. It is common to observe heart failure in pathologies associated to bad glucose handling for ATP production, as insulin resistance and diabetes. Metabolic syndrome, which comprehends both pathologies, has been correlated with low testosterone blood levels (Saad \& Gooren, 2009, 2011). It has been recently postulated that decrease in testosterone is a link between metabolic syndrome and heart failure. Clinical trials have demonstrated that the administration of testosterone at physiological concentrations improved insulin sensitivity, reduced glycaemia and central obesity, and heart failure progression in men suffering metabolic syndrome (Cook \& Romashkan, 2011). In addition to clinical trials, there are new studies related to testosterone effects on glucose metabolism. It has been described that testosterone is necessary to maintenance insulin and glucose concentration in blood. Recent reports have shown an important role for testosterone in the mobilization of glucose transporter GLUT4 to the plasma membrane in skeletal muscle, liver and fat tissue (Muthusamy et al., 2007, 2009).

In spite, elevated testosterone administration in humans is usually associated with the development of cardiac hypertrophy and heart failure; there are several studies that examine the relationship between the testosterone supplementation and heart failure with non positive correlation between them. Nowadays, several clinical trials lead to propose that testosterone supplementation at physiological doses could be a treatment for men with metabolic syndrome and heart failure (Pugh et al., 2000). The effect of testosterone as a metabolic modulator could improve insulin sensitivity and glucose uptake in the heart, which could lead to an increase in ATP production when cardiac output increases. However, evidences about the metabolic properties of testosterone on heart muscle come from observational studies. Research on the molecular mechanisms implicated in the metabolic testosterone actions is required.

\section{Integrated model for androgen action}

Androgens diffuse across plasma membrane due to their lipophilic nature. Once inside the cell, they are recognized by the cytosolic androgen receptor, which forms a complex with its ligand. This complex works as a transcription factor, which translocates to cell nucleus, binds to DNA and promotes the activation of several genes (Beato, 1989). This is called the 
classic or genomic androgen response pathway. On the other hand, it has been reported that androgens, exert a rapid, non-genomic effect mediated by a putative plasma membrane receptor. Its activation implicates participation of kinases, intracellular calcium oscillations and transcription factor activation, among other fast events.

Cardiomyocytes are terminally differentiated cells. Cardiac hypertrophy is characterized by an increase in cell size and protein synthesis and reactivation of a fetal gene program. Emerging evidence indicate that androgen action involves a crosstalk between genomic and nongenomic mechanisms. These could imply a two-step process, where both non-genomic and genomic effects occur sequentially (Figure 2). First, fast effects would be generated at the plasma membrane level with second messenger participation. Second, there would be gene activation; the pathways used by each cell type could provide specificity to the signal through a cooperative mechanism, which can act in a concerted form.

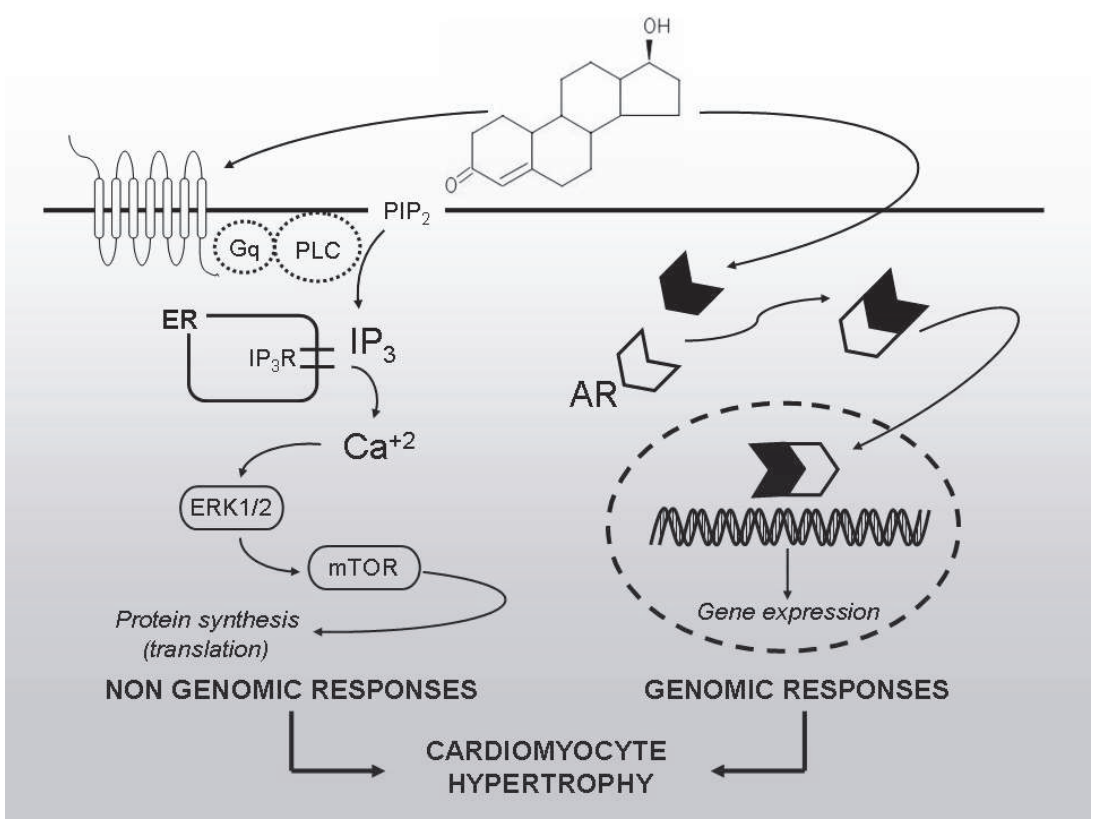

Fig. 2. Integrated mechanism for testosterone effects in cardiomyocytes. In cardiomyocytes, testosterone activates plasma membrane androgen receptors coupled to heterotrimeric $\mathrm{Gq}$ protein. G $\beta$ y dimers activate phospholipase $\mathrm{C}$ (PLC), which locally produces inositol $\mathrm{IP}_{3}$ thus activating $\mathrm{IP}_{3}$ receptors $\left(\mathrm{IP}_{3} \mathrm{R}\right)$. The consequent $\mathrm{Ca}^{2+}$ increase leads to the activation of several pathways, including the MEK/ERK/mTOR axis. These responses combined induce a series of genomic changes that lead to increased gene expression and increased protein synthesis, ultimately leading to cardiac hypertrophy.

While studying these hypertrophy effects on cardiomyocytes, our laboratory determined that testosterone uses a cooperative mechanism between the genomic and nongenomic pathways to produce the hypertrophic growth of cardiac cells. Thus, with normal levels of androgens the interactions among signaling pathways lead to the maintained health of cardiac cells, whereas high doses recruit additional signals which are hypertrophic. As 
depicted in Figure 2, testosterone activates a plasma membrane G-protein coupled receptor, a signaling pathway that results in a nongenomic mechanism. Activation of this pathway facilitates the hydrolysis of phosphatidylinositol 4,5-bisphosphate by phospholipase C, thereby generating diacylglycerol and $\mathrm{IP}_{3} . \mathrm{IP}_{3}$ mediates opening of $\mathrm{IP}_{3}$ receptors in the sarcoplasmatic reticulum, which in turn produce rapid (1-5 $\mathrm{min}$ ) $\mathrm{Ca}^{2+}$ release (Vicencio et al., 2006). Similar effects of testosterone have been identified in T-cells, skeletal muscle and neuroblastoma cells (Benten et al., 1999; Estrada et al., 2003, 2006). In cardiomyocytes, nongenomic signals activate the extracellular signal-regulated kinase (ERK) and the mTOR pathways. Activation of $\mathrm{Ca}^{2+} / \mathrm{ERK} / \mathrm{mTOR}$ axis is independent of androgen receptor.

The anabolic properties of testosterone indicate that this hormone regulate multiple genes involved in growth and metabolism. Traditionally, ligand-dependent androgen receptors act on DNA within the nucleus and in this compartment there is cross-talk among the nuclear receptors and cytosolic signaling. We have determined that testosterone induce a hypertrophic pattern in cardiomyocytes, evaluated as increase in the expression of fetal proteins, cardiomyocyte size, and protein synthesis. Hypertrophy effects of testosterone were blocked by either inhibition of mTOR or androgen receptor (Altamirano et al., 2009). We propose that cell growth produced by androgens require both androgen receptor activity and translation control through mTOR signaling pathway. Thus, both mTOR pathway and androgen receptor could control protein synthesis by a coordinated mechanism, where mTOR regulates translation and the intracellular androgen receptor regulates gene expression.

\section{Perspective}

The role of sex steroid hormones in modulating cardiovascular function is of the highest importance, given that androgen deficiency is strongly associated with common medical conditions including metabolic syndrome, obesity, diabetes, hypertension and atherosclerosis. However, cardiovascular side effects of high doses of anabolic/androgen steroid reduce its actual therapeutic use. Research in this field is necessary to know the real cardiovascular effects of androgens and to elaborate future optimal therapeutic replacement protocols.

\section{Acknowledgment}

This work was supported by FONDECYT grant 1090276.

\section{References}

Akkad, A. A.; Halligan, A. W.; Abrams, K.; \& al-Azzawi, F. (1997). Differing responses in blood pressure over 24 hours in normotensive women receiving oral or transdermal estrogen replacement therapy. Obstet Gynecol, 89, 97-103.

Alexandersen, P.; Haarbo, J.; Byrjalsen, I.; Lawaetz, H.; \& Christiansen, C. (1999). Natural androgens inhibit male atherosclerosis: a study in castrated, cholesterol-fed rabbits. Circ Res, 84, 813-819.

Altamirano, F.; Oyarce, C.; Silva, P.; Toyos, M.; Wilson, C.; Lavandero, S.; Uhlen, P.; \& Estrada, M. (2009). Testosterone induces cardiomyocyte hypertrophy through mammalian target of rapamycin complex 1 pathway. J Endocrinol 202, 299-307. 
Antos, C. L.; McKinsey, T. A.; Frey, N.; Kutschke, W.; McAnally, J.; Shelton, J. M.; Richardson, J. A.; Hill, J. A. \& Olson, E. N. (2002). Activated glycogen synthase-3 beta suppresses cardiac hypertrophy in vivo. Proc Natl Acad Sci U S A, 99, 907-912.

Bai, C. X.; Namekata, I.; Kurokawa, J.; Tanaka, H.; Shigenobu, K, \& Furukawa, T. (2005). Role of nitric oxide in $\mathrm{Ca}^{2+}$ sensitivity of the slowly activating delayed rectifier $\mathrm{K}+$ current in cardiac myocytes. Circ Res, 96, 64-72.

Bai, C. X.; Takahashi, K.; Masumiya, H.; Sawanobori, T.; \& Furukawa, T. (2004). Nitric oxidedependent modulation of the delayed rectifier $\mathrm{K}+$ current and the L-type $\mathrm{Ca}^{2+}$ current by ginsenoside Re, an ingredient of Panax ginseng, in guinea-pig cardiomyocytes. Br J Pharmacol, 142, 567-575.

Beato, M. (1989). Gene regulation by steroid hormones. Cell, 56, 335-44.

Benten, W. P.; Lieberherr, M.; Giese, G.; Wrehlke, C.; Stamm, O.; Sekeris, C. E.; Mossmann, H.; \& Wunderlich, F. (1999). Functional testosterone receptors in plasma membranes of T cells. FASEB J, 13, 123-133.

Cabral, A. M.; Antonio, A.; Moyses, M. R.; \& Vasquez, E. C. (1988a). Left ventricular hypertrophy differences between male and female renovascular hypertensive rats. Braz J Med Biol Res, 21, 633-635.

Cabral, A. M.; Vasquez, E. C.; Moyses, M. R.; \& Antonio, A. (1988b). Sex hormone modulation of ventricular hypertrophy in sinoaortic denervated rats. Hypertension, 11, 193-197.

Cavasin, M. A.; Tao, Z. Y.; Yu, A. L.; \& Yang, X. P. (2006). Testosterone enhances early cardiac remodeling after myocardial infarction, causing rupture and degrading cardiac function. Am J Physiol Heart Circ Physiol, 290, H2043-2050.

Cook, N. L.; \& Romashkan, S. (2011). Why do we need a trial on the effects of testosterone therapy in older men? Clin Pharmacol Ther, 89, 29-31.

Ding, A. Q.; \& Stallone, J. N. (2001). Testosterone-induced relaxation of rat aorta is androgen structure specific and involves $\mathrm{K}+$ channel activation. J Appl Physiol, 91, 2742-2750.

Dubey, R. K.; Oparil, S.; Imthurn, B.; \& Jackson, E. K. (2002). Sex hormones and hypertension. Cardiovasc Res, 53, 688-708.

English, K. M.; Jones, R. D.; Jones, T. H.; Morice, A. H.; \& Channer, K. S. (2001). Gender differences in the vasomotor effects of different steroid hormones in rat pulmonary and coronary arteries. Horm Metab Res, 33, 645-652.

English, K. M.; Mandour, O.; Steeds, R. P.; Diver, M. J.; Jones, T. H.; \& Channer, K. S. (2000). Men with coronary artery disease have lower levels of androgens than men with normal coronary angiograms. Eur Heart J, 21, 890-894.

Estrada, M.; Espinosa, A.; Muller, M.; \& Jaimovich, E. (2003). Testosterone stimulates intracellular calcium release and mitogen-activated protein kinases via a $G$ proteincoupled receptor in skeletal muscle cells. Endocrinology, 144, 3586-3597.

Estrada, M.; Liberona, J. L.; Miranda, M.; \& Jaimovich, E. (2000). Aldosterone- and testosterone-mediated intracellular calcium response in skeletal muscle cell cultures. Am J Physiol Endocrinol Metab, 279, E132-139.

Estrada, M.; Uhlen, P.; \& Ehrlich, B. E. (2006). Ca2+ oscillations induced by testosterone enhance neurite outgrowth. J Cell Sci, 119, 733-743. 
Fogari, R.; Preti, P.; Zoppi, A.; Fogari, E.; Rinaldi, A.; Corradi, L.; \& Mugellini, A. (2005). Serum testosterone levels and arterial blood pressure in the elderly. Hypertens Res, $28,625-630$.

Frey, N.; \& Olson, E. N. (2002). Modulating cardiac hypertrophy by manipulating myocardial lipid metabolism? Circulation, 105, 1152-1154.

Frey, N.; \& Olson, E. N. (2003). Cardiac hypertrophy: the good, the bad, and the ugly. Annu Rev Physiol, 65, 45-79.

Golden, K. L.; Marsh, J. D.; \& Jiang, Y. (2004). Testosterone regulates mRNA levels of calcium regulatory proteins in cardiac myocytes. Horm Metab Res 36, 197-202.

Handelsman, D. J. and Liu, P. Y. (2005). Andropause: invention, prevention, rejuvenation. Trends Endocrinol Metab, 16, 39-45.

Hayward, C. S.; Webb, C. M.; \& Collins, P. (2001). Effect of sex hormones on cardiac mass. Lancet, 357, 1354-1356.

Heineke, J.; \& Molkentin, J. D. (2006). Regulation of cardiac hypertrophy by intracellular signalling pathways. Nat Rev Mol Cell Biol, 7, 589-600.

Hickson, R. C.; Galassi, T. M.; Kurowski, T. T.; Daniels, D. G.; \& Chatterton, R. T.; Jr. (1984). Androgen and glucocorticoid mechanisms in exercise-induced cardiac hypertrophy. Am J Physiol, 246, H761-767.

Ikeda, Y.; Aihara, K.; Sato, T.; Akaike, M.; Yoshizumi, M.; Suzaki, Y.; Izawa, Y.; Fujimura, M.; Hashizume, S.; Kato, M. et al. (2005). Androgen receptor gene knockout male mice exhibit impaired cardiac growth and exacerbation of angiotensin II-induced cardiac fibrosis. J Biol Chem, 280, 29661-29666.

Iliescu, R.; \& Reckelhoff, J. F. (2006). Testosterone and vascular reactivity. Clin Sci (Lond), 111, 251-252.

Izumo, S.; Lompre, A. M.; Matsuoka, R.; Koren, G.; Schwartz, K.; Nadal-Ginard, B.; \& Mahdavi, V. (1987). Myosin heavy chain messenger RNA and protein isoform transitions during cardiac hypertrophy. Interaction between hemodynamic and thyroid hormone-induced signals. J Clin Invest, 79, 970-977.

Jaffe, M. D. (1977). Effect of testosterone cypionate on postexercise ST segment depression. Br Heart J, 39, 1217-1222.

Jones, R. D.; Hugh Jones, T.; \& Channer, K. S. (2004). The influence of testosterone upon vascular reactivity. Eur J Endocrinol, 151, 29-37.

Jones, R. D.; Nettleship, J. E.; Kapoor, D.; Jones, H. T.; \& Channer, K. S. (2005). Testosterone and atherosclerosis in aging men: purported association and clinical implications. Am J Cardiovasc Drugs, 5, 141-154.

Jones, R. D.; Pugh, P. J.; Jones, T. H.; \& Channer, K. S. (2003). The vasodilatory action of testosterone: a potassium-channel opening or a calcium antagonistic action? $\mathrm{Br} \mathrm{J}$ Pharmacol, 138, 733-744.

Kapoor, D.; Aldred, H.; Clark, S.; Channer, K. S.; \& Jones, T. H. (2007). Clinical and biochemical assessment of hypogonadism in men with type 2 diabetes: correlations with bioavailable testosterone and visceral adiposity. Diabetes Care, 30, 911-917.

Kaushik, M.; Sontineni, S. P.; \& Hunter, C. (2010). Cardiovascular disease and androgens: a review. Int J Cardiol, 142, 8-14.

Kienitz, T.; \& Quinkler, M. (2008). Testosterone and blood pressure regulation. Kidney Blood Press Res, 31, 71-79. 
Krenning, G.; Zeisberg, E. M.; \& Kalluri, R. (2010) The origin of fibroblasts and mechanism of cardiac fibrosis. J Cell Physiol, 225, 631-637.

Li, Y.; Kishimoto, I.; Saito, Y.; Harada, M.; Kuwahara, K.; Izumi, T.; Hamanaka, I.; Takahashi, N.; Kawakami, R.; Tanimoto, K. et al. (2004). Androgen contributes to gender-related cardiac hypertrophy and fibrosis in mice lacking the gene encoding guanylyl cyclase-A. Endocrinology, 145, 951-958.

Liu, P. Y.; Death, A. K.; \& Handelsman, D. J. (2003). Androgens and cardiovascular disease. Endocr Rev, 24, 313-340.

Liu, X. K.; Katchman, A.; Whitfield, B. H.; Wan, G.; Janowski, E. M.; Woosley, R. L. \& Ebert, S. N. (2003). In vivo androgen treatment shortens the QT interval and increases the densities of inward and delayed rectifier potassium currents in orchiectomized male rabbits. Cardiovasc Res, 57, 28-36.

Malkin, C. J.; Pugh, P. J.; Jones, R. D.; Kapoor, D.; Channer, K. S.; \& Jones, T. H. (2004). The effect of testosterone replacement on endogenous inflammatory cytokines and lipid profiles in hypogonadal men. J Clin Endocrinol Metab, 89, 3313-3318.

Malkin, C. J.; Pugh, P. J.; West, J. N.; van Beek, E. J.; Jones, T. H.; \& Channer, K. S. (2006). Testosterone therapy in men with moderate severity heart failure: a double-blind randomized placebo controlled trial. Eur Heart J, 27, 57-64.

Maron, B. J.; Roberts, W. C.; Edwards, J. E.; McAllister, H. A.; Jr.; Foley, D. D.; \& Epstein, S. E. (1978). Sudden death in patients with hypertrophic cardiomyopathy: characterization of 26 patients with functional limitation. Am J Cardiol, 41, 803-810.

Maron, B. J.; Roberts, W. C.; McAllister, H. A.; Rosing, D. R.; \& Epstein, S. E. (1980). Sudden death in young athletes. Circulation, 62, 218-229.

Marsh, J. D.; Lehmann, M. H.; Ritchie, R. H.; Gwathmey, J. K.; Green, G. E.; \& Schiebinger, R. J. (1998). Androgen receptors mediate hypertrophy in cardiac myocytes. Circulation, 98, 256-261.

McCrohon, J. A.; Death, A. K.; Nakhla, S.; Jessup, W.; Handelsman, D. J.; Stanley, K. K.; \& Celermajer, D. S. (2000). Androgen receptor expression is greater in macrophages from male than from female donors. A sex difference with implications for atherogenesis. Circulation, 101, 224-226.

Muthusamy, T.; Dhevika, S.; Murugesan, P.; \& Balasubramanian, K. (2007). Testosterone deficiency impairs glucose oxidation through defective insulin and its receptor gene expression in target tissues of adult male rats. Life Sci, 81, 534-542.

Muthusamy, T.; Murugesan, P.; \& Balasubramanian, K. (2009). Sex steroids deficiency impairs glucose transporter 4 expression and its translocation through defective Akt phosphorylation in target tissues of adult male rat. Metabolism, 58, 1581-1592.

Neglia, D.; De Caterina, A.; Marraccini, P.; Natali, A.; Ciardetti, M.; Vecoli, C.; Gastaldelli, A.; Ciociaro, D.; Pellegrini, P.; Testa, R. et al. (2007). Impaired myocardial metabolic reserve and substrate selection flexibility during stress in patients with idiopathic dilated cardiomyopathy. Am J Physiol Heart Circ Physiol, 293, H3270-3278.

Pham, T. V.; Sosunov, E. A.; Gainullin, R. Z.; Danilo, P.; Jr.; \& Rosen, M. R. (2001). Impact of sex and gonadal steroids on prolongation of ventricular repolarization and arrhythmias induced by I(K)-blocking drugs. Circulation, 103, 2207-2212.

Pripp, U.; Hall, G.; Csemiczky, G.; Eksborg, S.; Landgren, B. M.; \& Schenck-Gustafsson, K. (1999). A randomized trial on effects of hormone therapy on ambulatory blood 
pressure and lipoprotein levels in women with coronary artery disease. J Hypertens, $17,1379-1386$.

Proud, C. G. (2004). Ras, PI3-kinase and mTOR signaling in cardiac hypertrophy. Cardiovasc Res, 63, 403-413.

Pugh, P. J.; English, K. M.; Jones, T. H.; \& Channer, K. S. (2000). Testosterone: a natural tonic for the failing heart? QJM, 93, 689-694.

Rautaharju, P. M.; Prineas, R. J.; Kadish, A.; Larson, J. C.; Hsia, J.; \& Lund, B. (2006). Normal standards for QT and QT subintervals derived from a large ethnically diverse population of women aged 50 to 79 years (the Women's Health Initiative [WHI]). Am J Cardiol, 97, 730-737.

Saad, F.; \& Gooren, L. (2009). The role of testosterone in the metabolic syndrome: a review. J Steroid Biochem Mol Biol, 114, 40-3.

Saad, F, \& Gooren, L. J. (2011). The role of testosterone in the etiology and treatment of obesity, the metabolic syndrome, and diabetes mellitus type 2. J Obes, 2011.

Shioi, T.; McMullen, J. R.; Tarnavski, O.; Converso, K.; Sherwood, M. C.; Manning, W. J.; \& Izumo, S. (2003). Rapamycin attenuates load-induced cardiac hypertrophy in mice. Circulation, 107, 1664-1670.

Simental, J. A.; Sar, M.; \& Wilson, E. M. (1992). Domain functions of the androgen receptor. J Steroid Biochem Mol Biol, 43, 37-41.

Stamler, J.; Stamler, R.; Riedlinger, W. F.; Algera, G.; \& Roberts, R. H. (1976). Hypertension screening of 1 million Americans. Community Hypertension Evaluation Clinic (CHEC) program, 1973 through 1975. JAMA, 235, 2299-2306.

Stanley, W. C.; Recchia, F. A.; \& Lopaschuk, G. D. (2005). Myocardial substrate metabolism in the normal and failing heart. Physiol Rev, 85, 1093-1129.

Sullivan, M. L.; Martinez, C. M.; Gennis, P.; \& Gallagher, E. J. (1998). The cardiac toxicity of anabolic steroids. Prog Cardiovasc Dis, 41, 1-15.

Takano, H.; Komuro, I.; Zou, Y.; Kudoh, S.; Yamazaki, T.; \& Yazaki, Y. (1996). Activation of p70 S6 protein kinase is necessary for angiotensin II-induced hypertrophy in neonatal rat cardiac myocytes. FEBS Lett, 379, 255-259.

Thijs, L.; Fagard, R.; Forette, F.; Nawrot, T.; \& Staessen, J. A. (2003). Are low dehydroepiandrosterone sulphate levels predictive for cardiovascular diseases? A review of prospective and retrospective studies. Acta Cardiol, 58, 403-410.

van der Vusse, G. J.; van Bilsen, M.; \& Glatz, J. F. (2000). Cardiac fatty acid uptake and transport in health and disease. Cardiovasc Res, 45, 279-293.

van der Vusse, G. J.; van Bilsen, M.; Glatz, J. F.; Hasselbaink, D. M.; \& Luiken, J. J. (2002). Critical steps in cellular fatty acid uptake and utilization. Mol Cell Biochem, 239, 915.

Vicencio, J. M.; Ibarra, C.; Estrada, M.; Chiong, M.; Soto, D.; Parra, V.; Diaz-Araya, G.; Jaimovich, E.; \& Lavandero, S. (2006). Testosterone induces an intracellular calcium increase by a nongenomic mechanism in cultured rat cardiac myocytes. Endocrinology, 147, 1386-1395.

Webb, C. M.; McNeill, J. G.; Hayward, C. S.; de Zeigler, D.; \& Collins, P. (1999). Effects of testosterone on coronary vasomotor regulation in men with coronary heart disease. Circulation, 100, 1690-1696. 
Weinberg, E. O.; Thienelt, C. D.; Katz, S. E.; Bartunek, J.; Tajima, M.; Rohrbach, S.; Douglas, P. S.; \& Lorell, B. H. (1999). Gender differences in molecular remodeling in pressure overload hypertrophy. J Am Coll Cardiol, 34, 264-273.

Zhou, S. H.; Wong, S.; Rautaharju, P. M.; Karnik, N.; \& Calhoun, H. P. (1992). Should the JT rather than the QT interval be used to detect prolongation of ventricular repolarization? An assessment in normal conduction and in ventricular conduction defects. J Electrocardiol, 25 Suppl, 131-136. 


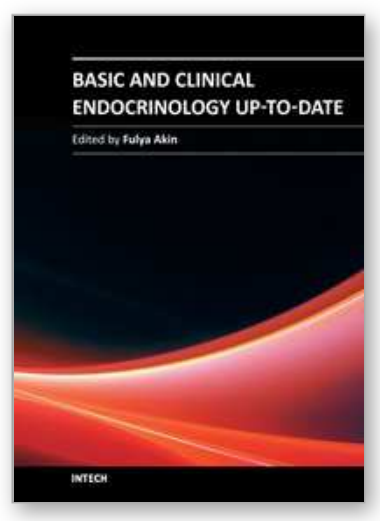

\author{
Basic and Clinical Endocrinology Up-to-Date \\ Edited by Dr. Fulya Akin
}

ISBN 978-953-307-340-8

Hard cover, 350 pages

Publisher InTech

Published online 17, October, 2011

Published in print edition October, 2011

This book provides the most up-to-date information on the basic and clinical aspects of endocrinology. It offers both researchers and clinicians experts, gold-standard analysis of endocrine research and translation into the treatment of diseases such as insulinoma, endocrine disease in pregnancy and steroid induced osteoporosis. Investigates both the endocrine functions of the kidneys and how the kidney acts as a target for hormones from other organ systems. Presents a uniquely comprehensive look at all aspects of endocrine changes in pregnancy and cardiovascular effects of androgens.

\title{
How to reference
}

In order to correctly reference this scholarly work, feel free to copy and paste the following:

Carlos Wilson, Rodrigo Maass and Manuel Estrada (2011). Cardiovascular Effects of Androgens, Basic and Clinical Endocrinology Up-to-Date, Dr. Fulya Akin (Ed.), ISBN: 978-953-307-340-8, InTech, Available from: http://www.intechopen.com/books/basic-and-clinical-endocrinology-up-to-date/cardiovascular-effects-ofandrogens

\section{INTECH}

open science | open minds

\section{InTech Europe}

University Campus STeP Ri

Slavka Krautzeka 83/A

51000 Rijeka, Croatia

Phone: +385 (51) 770447

Fax: +385 (51) 686166

www.intechopen.com

\section{InTech China}

Unit 405, Office Block, Hotel Equatorial Shanghai

No.65, Yan An Road (West), Shanghai, 200040, China

中国上海市延安西路65号上海国际贵都大饭店办公楼 405 单元

Phone: +86-21-62489820

Fax: +86-21-62489821 
(C) 2011 The Author(s). Licensee IntechOpen. This is an open access article distributed under the terms of the Creative Commons Attribution 3.0 License, which permits unrestricted use, distribution, and reproduction in any medium, provided the original work is properly cited. 